\title{
THE EFFECT OF MOLE DRAINAGE AND WINTER PUGGING ON GRASSLAND PRODUCTION
}

R. S. SCOTT, Scientific Officer, Invermay Research Station, Department of Agriculture, Mosgiel

Drainage has been of primary importance in the development of much of New Zealand's lowland country for agricultural use. Without drainage much land is too wet to carry stock and machinery (in a physical sense) or to permit the establishment and maintenance of suitable pasture species. The necessity to drain such land if it is to be farmed at all is beyond dispute.

In the effort to increase production on low-lying foothill country farmers are frequently encouraged to implement farm drainage schemes. On such country in Otago and Southland high soil moisture levels are normally a problem from early June to the end of August. As an example the 6-yearly average of $0=3$ in. soil moisture levels obtained at Invermay are shown in Fig. 1. The moisture equivalent (the approximate level at which drainage would occur), for this soil layer is also shown, together with the

MEAN 0-3" SOIL MOISTURE LEVEL (1957-62)

ON UNDRAINED TREATMENTS.

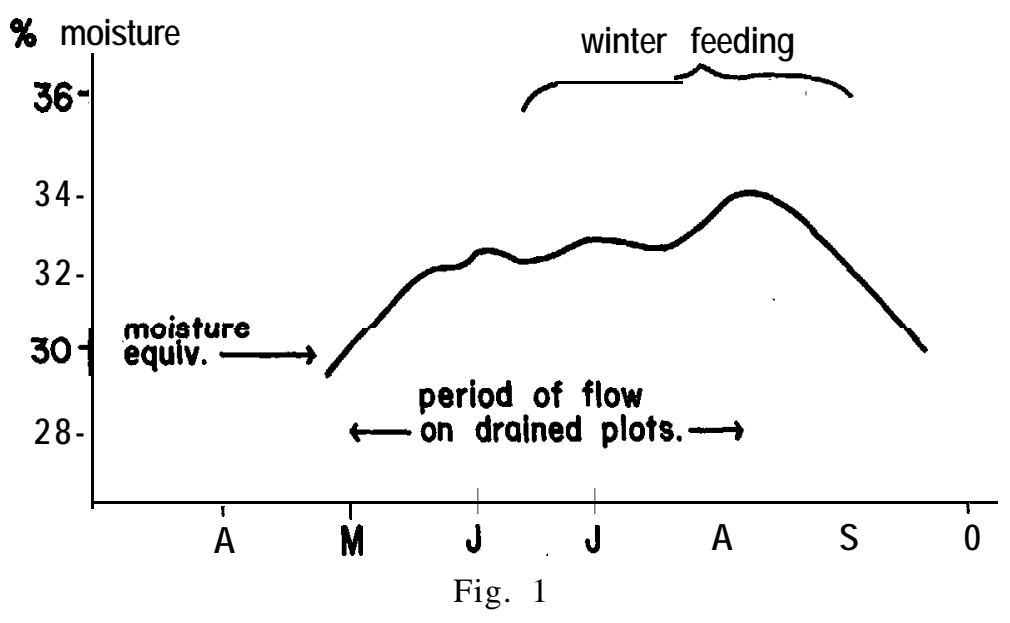

119 
average time at which drains first commenced and finally ceased discharging water.

Under the prevailing pattern of winter feeding in these dominantly sheep raising districts swedes, chou moellier, and hay form the basis of the feed supply, with the use of saved grass an innovation in recent years. Normally sheep are run on swedes or chou moellier during the day, and at night they are put in a run-off paddock where hay has been fed out. Generally only one run-off paddock is used, and this is the paddock due to be ploughed in the following year. The remainder of the farm carries few stock during this period. The time at which winter feeding begins and ends is indicated in Fig. 1. This period coincides approximately with the period of high soil moisture levels.

It was under the conditions outlined that the experiment to be described was designed. It was commenced in 1957 with the main purpose of determining what pasture production increases would follow drainage. After the experiment had been in progress for 2 years different grazing treatments were introduced to see what effect winter grazing, with its unavoidable pugging, would exert. Further it was of interest to know the extent to which any deleterious effects of pugging could be reduced by drainage.

The trial was conducted at Invermay Research Station, approximately 10 miles west of Dunedin on foothill country adjoining the Taieri Plains. The soil is a yellow-grey to yellow-brown intergrade and consists of a silt loan overlying clay at a depth of 9 in.

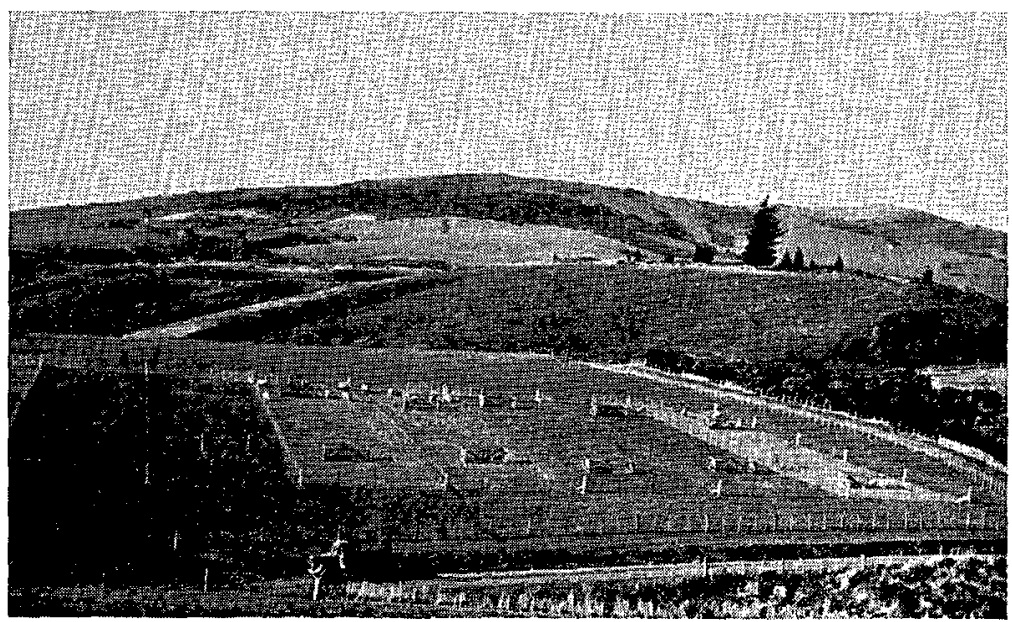

Fig. 2-Portion of the experiment during grazing in winter. 
A site of $1 \frac{1}{2}$ acres was selected on the rolling foothill country of gradient 1 in 7 . The pasture was 3 years old and by point analysis comprised approximately 35 per cent ryegrass, 6 per cent cocksfoot, 4 per cent timothy, 15 per cent browntop, 10 per cent Yorkshire fog, 4 per cent poa species, and 18 per cent white clover. The area was subdivided into six quarter-acre plots in October 1956. Three of the plots were left undrained while the other three were drained by pulling moles across them and carrying water off the site with tiles running down the fence lines. Very effective drainage resulted. Moles were pulled to within only 3 or 4 feet of the edges of the plots to keep the effect. of drainage precisely within the drained plots.

For the first and second winters the plots were not grazed and pugging was avoided. Mob stocking was practised at a concentration of approximately 60 ewes/acre and each plot was given identical grazing.

In 1959 each drained and undrained plot was subdivided. One half of each original plot was selected at random as the winter grazing treatment, and the other had stock kept off it during winter when pugging was likely. In practice, since winter growth was negligible, late autumn growth was saved on all treatments. The plots generally carried a pasture 3 to 4 in high at the time of the first winter grazing.

An important point in the management of this experiment was that grazing was only of sufficient duration to utilise grass available. The first winter grazing treatment was applied in mid-winter and 3 to 4 weeks were allowed for recovery from soiling before the final winter grazing was applied. By the end of winter the winter-grazed pastures were bare while the treatments not grazed in winter carried 5 to 6 in of grass when they were grazed down in early September. On the latter treatment grazing was not done until the moisture level had dropped sufficiently to avoid pugging.

In the heading of this paper I deliberately chose the word "pugging" since it refers to the "footprint of a beast" (Concise Oxford) which I have interpreted as a general term incorporating the more specific terms of "puddling", where a surface slurry results, and "compaction", where the pore space in the soil decreases and where clearly defined hoof prints result if the load is sufficient.

On undrained treatments pugging followed winter grazing. Hooves generally penetrated to a depth of 13 in and a surface slurry was ultimately formed. This differed from the effects on drained treatments, where there were clearly defined but shallow hoof prints without any sign of slurrying. 


\section{Effect of Drainage}

\section{RESULTS}

In the first two years before the factor of winter grazing was introduced, drainage had no significant effect on annual or seasonal pasture yields.

From 1959 to 1963 where winter grazing was practised on half the drained and half the undrained treatments there were interactions between the four treatments. For this reason the results given in Fig 3 show the yields from individual treatments. For brevity only seasonal and annual yields in which there were significant differences are shown.

\section{SEASONAL \& ANNUAL YIELDS 1959163.}

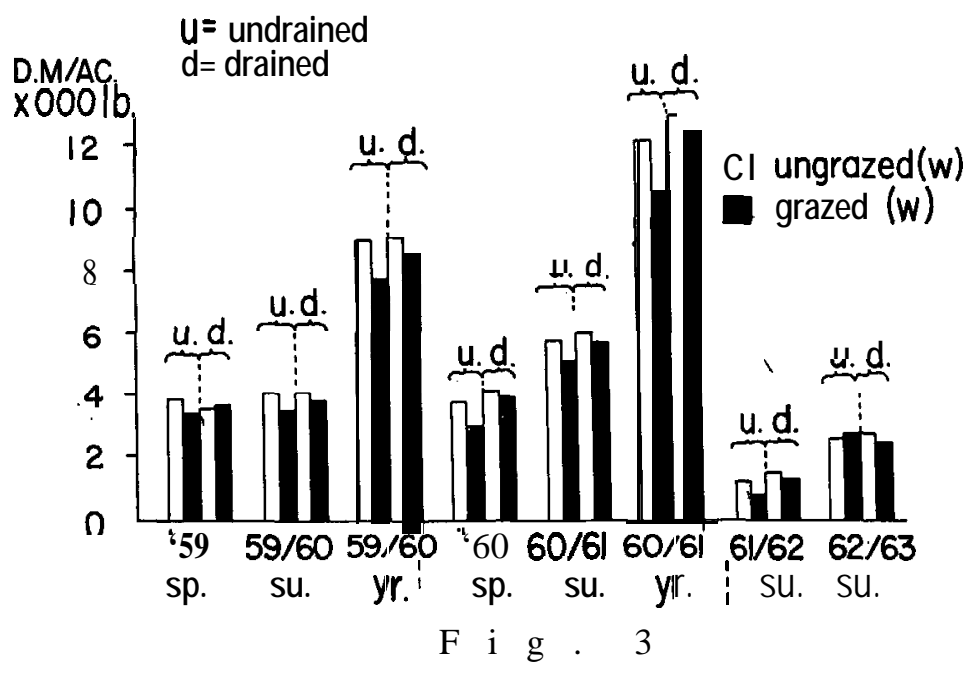

Where there was no winter grazing drainage increased yields only in 1960-61, when annual yields were increased by approximately 6 per cent. Both spring and summer yields contributed to this effect.

Where there was winter grazing the effect of drainage was much more marked and seasonal responses to drainage went as high as 33 per cent. Annual yields were 11 per cent and 18 per cent higher in favour of drainage in 1959-60 and 1960-61 respectively.

Results for summer 1962-63 are of interest, as undrained treatments significantly outyielded those which were drained. Extremely dry weather had reduced moisture levels close to the wilting point. Higher moisture, levels were recorded on undrained treatments at that time-presumably a carryover effect from late winter. 
Changes in pasture composition were measured annually by point analysis and also in 1961-62 and 1962-63 by herbage dissection. In the point analysis of 1961 (autumn) and in the herbage dissection of summer 196 l-62 slightly more cocksfoot was recorded on drained treatments. The dissection in all seasons of 1962-63 showed higher yields of cocksfoot on drained treatments.

In autumn 1963 ryegrass yields were slightly depressed by drainage.

The pasture composition changes outlined above were not influenced by the grazing treatment. In autumn 1963 coocksfoot yields were dependent on both treatments, in that drainage increased yields more when drained treatments were also winter grazed.

The small yield response to drainage could be associated with changes in composition, particularly the increased summer production of cocksfoot. Changes in soil physical conditions could have played some part in altering absolute yields, quite apart from the effects on pasture composition. Gradwell (1960) illustrated the serious reduction in the volume of air-filled pore space occurring in a saturated soil on a Manawatu silt loan. On undrained treatments in the Invermay experiment it is likely that a similar situation will have prevailed.

Soil temperatures at $\frac{1}{2}$ and. 4 in. depths were recorded weekly over each of the six winters. Results (Fig. 4) give no confirmation to the assertion (Scott and Mayo 1961) that drained soils warm up more rapidly and thereby give greater plant growth,

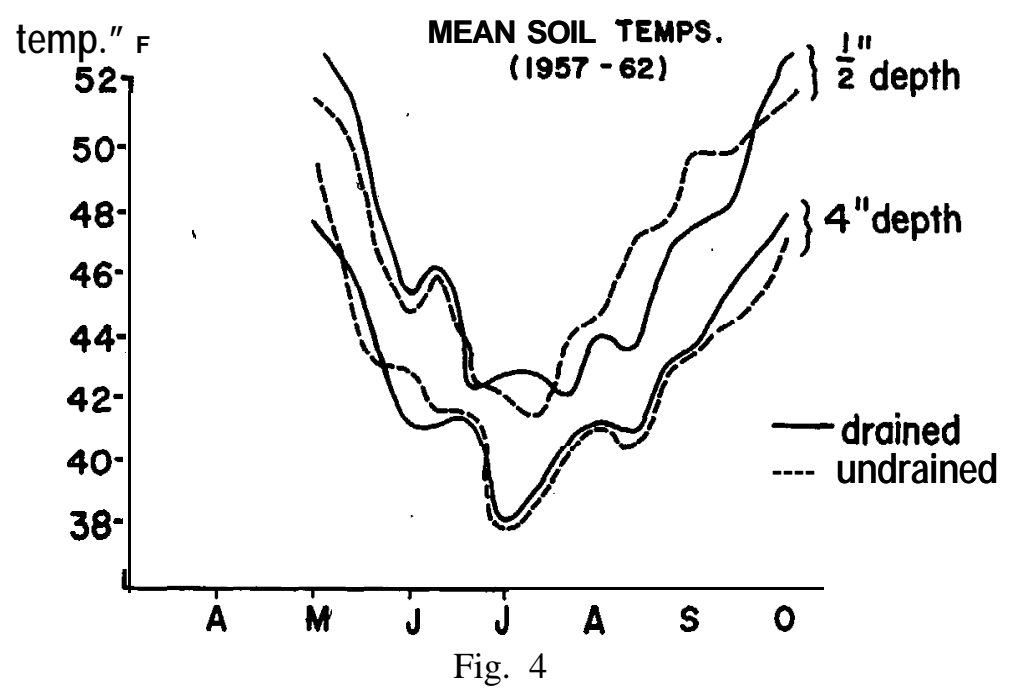

123 


\section{Effect of Winter Grazing}

Comparing yields on ungrazed and winter grazed treatments in the absence of drainage it can be seen that large reductions occurred.

In 1959-60 and 1960-61 winter grazing depressed pasture yields by 16 per cent and 15 per cent respectively. Fig. 3 shows that this yield depression was as great in summer as in spring.

Winter grazing of the drained treatments also depressed yields, but not to the same extent as it did.on undrained treatments. Yield depressions for 1959-60 and 1960-61 were 6 per cent and 4 per cent respectively.

Point analysis in 1960 (autumn) showed that winter grazing caused a significant increase in cover hits on poa species. In autumn 1962 and summer 1962-63 winter grazing decreased yields of poa species, although the amount of production involved amounted to only $30 \mathrm{lb}$ of dry matter/acre. Yorkshire fog was decreased slightly (when measured by point analysis in 1960 and 1963). Herbage dissection showed a similar trend.

In 1961-62 and 1962-63 annual, yields of white clover were increased by 27 per cent and 41 per cent on winter-grazed treatments. This difference was largely confined to summer months and involved approximately $400 \mathrm{lb}$ of dry matter/acre.

Winter grazing reduced yields of cocksfoot in all seasons of 1962-63.

These changes in composition are of interest in the agreement they show with the results given by Edmonds at a previous conference of this Association (1960). They show that under wet conditions white clover was definitely insensitive to treading, ryegrass and timothy relatively insensitive, cocksfoot and Yorkshire fog sensitive, poa species variable in sensitivity.

Perhaps of greatest interest in regard to pasture composition in this experiment is that, in spite of transitory changes in species produtcion and composition, no marked change in composition could be detected as a result of 6 years of drainage and 4 years of winter grazing.

TABLE I-VOLUME WEIGHT RESULTS ( $M$ easured after final grazing each year).

$\begin{array}{llcccc} & & \text { Ungrazed } & \text { Grazed } & \text { Probability } & \text { C.V.\% } \\ 1959 & \mathbf{0}-1 \frac{1}{2} \text { in } & 0.90 & 0.94 & \mathbf{p}<.2 & 4.4 \\ & \text { O-3 in } & 1.02 & 1.02 & \mathrm{P}>.5 & 2.8 \\ 1950 & \mathbf{0}-1 \frac{1}{2} \text { in } & 0.95 & 0.99 & \mathbf{p}<.05 & 1.5 \\ & 1 \frac{1}{2}-3 \text { in } & 1.16 & 1.17 & \mathrm{P}>.2 & 1.2 \\ 1961 & \mathbf{0}-1 \frac{1}{2} \text { in } & 0.88 & 0.94 & \mathbf{p}<.05 & 4.3 \\ & 1 \frac{1}{2}-3 \text { in } & 1.17 & 1.17 & \mathbf{p}>.5 & 2.7 \\ 1962 & \mathbf{0}-1 \frac{1}{2} \text { in } & 0.88 & 0.91 & \mathbf{p}<.5 & 6.1 \\ & 1 \frac{1}{2}-3 \text { in } & 1.17 & 1.20 & \mathrm{P}>.5 & 2.5\end{array}$


Changes in soil physical conditions will undoubtedly have had an impact on both absolute and relative yield of species. Volume weight determinations (Table 1) indicate a slight compaction in the top $1 \frac{1}{2}$ in. of soil as a result of winter grazing. There was no evidence of any accumulative effect on soil compaction over the 4 years. Increased compaction is normally indicative of a decrease in pore space, and in view of Gradwell's measurements of pore space on a saturated soil it is 'likely that any compaction in winter will have reduced air space to a serious level.

Recordings were taken of the load-bearing capacity of treatments with a self-recording continuous-stress type of penetrometer. Variability was low (C. of V. 4 to 6 per cent) and yet at no time was there any significant compaction down to a depth of 3 in. This does not discount the possibility suggested by O'Connor (1956) that where hooves penetrate deeply compaction may occur at some depth below the surface.

Puddling occurred each year on undrained treatments, but very little on drained treatments. Edmond (1958) found a reduction in yields following puddling. He attributed it to a reduction in gaseous diffusion and distinguished it from compaction, which exerted, if anything, favourable effects on yields. Thus puddling would appear to be an important change in soil characteristics, which would account for much of the reduction in yields after winter grazing.

To find a definite explanation for the effects of winter grazing is difficult. The experiment was designed to measure the net effect on pasture production of various treatments which are applied in practical farming. Because of this the winter grazing treatments involved compaction, puddling, defoliation, return of nutrients, and the maintenance of a closely grazed sward. On treatments not winter grazed no puddling occurred, greater compaction may have occurred as a consequence of temporary heavier stocking in spring, and defoliation and return of nutrients was later. With these variables it is not possible to isolate their separate contributions to treatment effects.

\section{CONCLUSIONS}

It is difficult to make any firm recommendations from the results of an experiment such as this, which has been conducted on only one soil type. However, certain principles have been established on which judgement can be based, depending on the soil type, the soil moisture problem, class of stock, and degree of pugging. These are:

1. Where winter grazing is not practised drainage is of doubtful value in increasing pasture production. 
2. Where winter grazing is practised the 'evidence shows that pasture production will suffer appreciably and that drainage will alleviate this damage to some extent.

It appears that under normal farm conditions drainage of paddocks which are frequently used for winter grazing or for movement of stock and machinery is warranted. The remainder of the farm could well be left undrained.

\section{Acknowledgements}

I wish to acknowledge the assistance of the staff of Invermay Research Station and of the Biometrics Section of the Department of Agriculture for the many statistical analyses.

The assistance of Mr J. Scott, Farm Advisory Officer (drainage), Department of Agriculture, Christchurch, who supervised the installation of the drainage system in these trials is greatly appreciated.

\section{References}

Edmond, D. B., 1958: N.Z. J. Agric. Res. 1: 652-659.

Edmond. D. B.. 1960: Proc. 22nd Conf. N.Z. Grassl. Assoc.: 111-121

Gradwell, M. W., 1960: N.Z. J. Agric. Res. 3: 663-674.

O’Connor, K., 1956: Proc. N.Z. Soc. Soil Sci. 2: 35-37.

Scott, D. F., Mayo, K. L.: "Farm Drainage". N.Z. Dept. of Agric. Bull. 286.

\section{DISCUSSION}

Q. (Mr Callaghan): In view of my recent remarks on the need for increasing the sheep population in New Zealand, it is pleasing to know that this aspect of development is being investigated. Were sheep weights recorded in the experiment?

A. No. The trial design and area was unsuited to animal experimentation.

Q. (Mr Lockhart): Were dry summers experienced during the course of this experiment?

A. Yes. The summer of 1961/62 was dry and during this period yields on treatments grazed in winter were higher than those not grazed. Whether this effect was dependent upon low soil moisture levels or not I cannot say. The dry summer of $1962 / 63$ resulted in slightly higher yields on undrained treatments as I described in my paper.

Q. (Mr Brassel): There appeared to be very little winter growth; would the results of your trial apply where there was more growth in winter?

A. My opinion is that greater benefits would be obtained from drainage than those I recorded. Also winter grazing would have been more detrimental on wet soils.

Q. I was interested in the fact that there was no cumulative soil compaction in this trial, indicating some recovery of the soil from pugging each year. The deleterious effect of grazing on pasture production may be due to the low soil fauna content of these soils. Was this the case?

A. The soil on which the experiment was conducted is not devoid of earthworms as is the nearby Hindon area which Dr O'Connor possibly has in mind. I doubt if the effects of winter grazing can be attributed to low soil fauna activity. 
Q. (Mr Campbell): I wonder whether treading had any effect on the flowering time of pasture species, particularly perennial ryegrass. A. The trial was closely grazed when flowering would occur and such observations were not possible.

Q. (Mr Cross): What was the rainfall intensity in the winter months?

A. Approximately May, 2 in, June $2 \frac{1}{2}$ in, July 2 in, and August, $1 \frac{3}{4}$ in.

Q. Will you comment on the 335 per cent increase in seasonal dry matter production from the trial?

A. This difference occurred in spring 1960 on plots drained which had also been winter grazed. It was the largest difference I obtained in the trial and illustrates how markedly pasture production can be reduced through not draining land that is winter grazed. 